\title{
PRESERVING METHODOLOGICAL CONSISTENCY: A REPLY TO RAFTERY, MCGEORGE \& WALTERS
}

J. Rooke, D. Seymour \& D. Crook

Published as:

Rooke, J., Seymour D. \& Crook, D. (1997) 'Preserving Methodological Consistency, a Reply to

Raftery, McGeorge and Walters', Construction Management and Economics, 15(5):491-494.

\begin{abstract}
Raftery et al (1997) criticise Seymour \& Rooke (1995) for setting out battle lines in their use of the terms rationalist and interpretive paradigms and argue that such dichotomies lead to a degeneration in research standards. Sharing their concern for research standards, in reply, we argue that Raftery et al's plea for methodological liberalism will itself undermine standards. Different research methods are required for different research purposes and are to be evaluated according to different criteria. These criteria must be made explicit. We state our own research purposes and make an initial attempt to set out some criteria against which we would wish our own research to be judged.
\end{abstract}

\section{Keywords}

Research methodology, research paradigms, methodological debate, construction management

It is gratifying that our recent essay on research paradigms (Seymour \& Rooke 1995) has drawn such a trenchant response (Raftery, McGeorge \& Walters 1997). It would be churlish of us to complain, after writing an article of critical intent, that the response to it should concentrate on the weakest part of our argument. It is unfortunate, however, that in attacking our use of the term 'paradigm' in the presentation of our critique, Raftery et al direct the focus of debate away from where we feel it should lie, with the choice between verstehen and causal explanations. We 
perceive three strands to their criticism of our distinction between rationalist and interpretive ${ }^{1}$ paradigms: first, that it constitutes the drawing up of battle lines and that the debate may generate more heat than light; second, that it is not possible to categorise studies according to the rationalist/ interpretive dichotomy; lastly, that methodological critiques such as ours can lead to a degeneration in standards of research. We will deal with each of these points in turn and then attempt to further explain our position.

First, the dangers of promoting unnecessary confrontation and acrimony within the research community. Raftery et al are right to point these out and we apologise unreservedly if our paper has given offence to anyone. This was not our intention. Unfortunately, their metaphor of military conflict does less to defuse any such feelings than to encourage them. We stress that our paper was not intended as an attack, but as constructive criticism. There was certainly no intention to ‘demonise' anybody.

Instead of the battle metaphor we would like to suggest another, provided by Anderson, Hughes and Sharrock (1986). Following Rorty (1980), they liken philosophy to a conversation. Unlike a battle, a conversation is not a zero sum game; there are no winners or losers - instead, all participants stand to gain.

"Each contribution has something to offer and something distinctive worth hearing. After all, a conversation is not a monologue, nor is it a ritual chant." (Anderson et al 1986:269)

Raftery et al have been very generous in thanking us for stimulating a debate, it is this generosity we would prefer to remember, rather than their image of young researchers doing each other to death like mythical warriors.

Secondly, they highlight the crudity of the interpretive/rationalist dichotomy, demonstrating its inappropriateness in categorising studies. They are quite correct in this. That the dichotomy should be used for such a purpose was never intended by us: it should be regarded only as a simplifying, explanatory device. Its purpose was to draw attention to some problems with current construction management research. Our use of the term paradigm owes much to the usage developed by Kuhn (1970), though it should be borne in mind that Kuhn himself doubted the strict applicability of the term to social studies. It would be more correct to see the two paradigms as different ways of thinking. Many papers will contain elements of each; this, indeed, is a serious

1 The term 'interpretive' follows the American writers who have been a profound influence on our thinking. The rather unwieldy spelling 'interpretative' in our original paper was adopted on the prompting of a referee. Now, with the appearance of a third, Australasian usage - 'interpretist', we have given up trying to please everyone and return to our original preference. 
problem in itself, as we will endeavour to explain below. Furthermore, each paradigm does not contain a single method, but several. For instance, within the interpretive paradigm there are those who set out to produce fundamental criticisms of the status quo and those, like ourselves, who seek to maintain a principled indifference to it - these diverse outlooks clearly require different methods of analysis for their fulfilment. It is to be hoped that some advocate of the former approach will, at some future date, outline this alternative position in these pages.

The dichotomy can be applied as a kind of standard against which studies are judged, such that they can be described as interpretive in this respect, rationalist in that, but even this is not our present intention. We would much prefer to focus on the real difficulties we see confronting construction management research, which we attempted to call attention to in our paper, but which Raftery et al unfortunately do not address.

Finally, the quote from Halsey (1996) highlights the dangers of sacrificing academic rigour. Loss of academic standards is indeed a grave danger and we stress most strongly that our intentions are exactly the opposite - to promote academic rigour, rather than to undermine it. We attempted to do this by criticising what we see as problems with current standards, which we labelled the rationalist paradigm. We are somewhat taken aback by Raftery et al's accusation that we did not sufficiently define the term rationalist. In a section headed 'The Dominant Rationalist Paradigm' (Seymour \& Rooke 1995:512-514), we spent almost two pages explaining what we meant by it. Surely it should be apparent from any reading of this passage that our intention is not to attack 'sane, judicious or reasonable' research, as Raftery et al charge; this would be nonsense. Others use the term 'positivist' as a synonym for 'rationalist' (Runeson 1997; Root, Fellows \& Hancock 1997); within the context of this debate, we find such a usage acceptable.

The multi-paradigm approach which Raftery et al advocate is not conducive to the aim of developing greater rigour. On the contrary, we would attribute the problems suffered in sociology to the prevalence of precisely this kind of do-as-you-please, methodological liberalism. For the unintended effect of advocating a multi-paradigm approach is to license all kinds of unexamined premises, methods and arguments. Such an approach merely avoids argument, in fact, by removing the need for agreement. Take for example Csete and Albrecht (1994), whom they quote with approval

"both paradigms ascribe to the same basic goal of research, to gain a better understanding of the world.”

But what constitutes a better understanding of the world? This is precisely what is at 
issue. It is our central contention that verstehen understandings rather than causal ones should be the aim of social research and that management studies is primarily a social discipline. In the final analysis, the two goals are incompatible, since the latter involves giving precedence to the views of the researcher/theorist and the former involves giving precedence to the views of those who are subjects of the research. As Wagner (1981:16) has pointed out, in the context of anthropological research

"every anthropological undertaking stands at a cross-roads: it can choose between an open-ended experience of mutual creativity [...] and a forcing of our own preconceptions onto other peoples.”

Wagner is not saying here that causal understandings are not viable. Nor is he denying that, in the course of our ordinary common sense reasoning, we combine causal and verstehen understandings to great practical effect. What he is pointing out is that if we are to engage in the rigorous pursuit of verstehen understanding, then we must restrain our natural propensity to give precedence to our own beliefs and opinions, over those of the subjects of our research. This restriction includes any causal understandings we may favour.

Of course we are not saying that researchers' opinions may not be valid. But surely academic rigour demands that we do not settle for mere opinion? Clearly Raftery et al do not understand this point. Indeed, they acknowledge as much

"We were puzzled to discover that according to Seymour and Rooke, attempting to find causal variables is 'inimical' to the 'special demands' of social research.”

They are so puzzled that they pass over it without further comment. Yet the problematic nature of causal analyses of social processes is crucial to our argument. This is because the kind of understanding, and therefore the kind of enquiry, which is best suited to the study of people is not causal, but conceptual (Ryle 1963; Blumer 1967; Coulter 1979; Winch 1990; Button, Coulter, Lee \& Sharrock 1995). The required analysis is an analysis of meaning, rather than analysis of causality. Approaches such as Csete and Albrecht's obscure such questions with anodyne platitudes such as 'we are all striving for the truth'. Of course, we would not wish to deny this, but such platitudes raise the discussion to a level of abstraction where the real problems we attempted to highlight become totally obscured.

All this raises the further question of how far our criticism of current practice extends. Are we in 
fact asserting that all research in construction management is social research? We are not in a position to give a precise answer to this question. However, we would point out that construction processes are carried out by people engaging in concerted social action. Recent research into the achievement of concrete cover (Shammas-Toma, Seymour \& Clark 1996, Seymour, ShammasToma \& Clark 1997) demonstrates that our approach bears upon what are often regarded as purely technical matters, more closely than many might assume.

We are left to wonder what precisely Raftery et al are advocating? They recognise that a paradigm is a 'conceptual framework or a "world view", yet they seem to require researchers and analysts to work within two (or more?) of these at the same time. They do not acknowledge the immense, perhaps insurmountable, difficulty of such a task. Indeed, elsewhere in their note they treat the whole question of paradigms as if it were merely a question of preferring one method over another. Choice of methods is itself an important topic, dealt with in Crook (1997) but such differences do not in themselves constitute paradigm shifts. Confusion over the use of such terms as 'paradigm', 'method' and 'methodology' are rife at present and those seeking clarification could do worse than consult two recent publications in our own field, Edum-Fotwe, Price \& Thorpe (1996) and Root et al (1997). Though we do not endorse the conclusions of either paper and, in particular, would warn against Edum-Fotwe et al's over-reliance on Haralambos \& Holborn (1991), we do at least find a greater clarity here on the distinction between method and paradigm.

Let us now attempt to clarify the issues as we see them. First, we see the paradigmatic, or methodological issue as being the question of what kind of understanding researchers and analysts should be trying to achieve. We do not rule out any methods a priori; it is the significance of the findings that these methods achieve which is at issue. Researchers and analysts must take a view on this. Not to do so leads to ontological relativism and the chaotic conflict which Halsey bemoans. For, once an insistence on rigorous academic standards is abandoned, the field is left open to unreasoned passion and empty rhetoric. We have criticised current standards, to be sure, but we will never consent to all standards being abandoned. The multi-paradigm approach, we fear, may be the first step on such a path, for it allows the possibility of evading definable standards by appealing to ever more abstract notions.

Part of what we object to in current practice is that it allows bad researchers to get away with a mechanistic application of formal procedure, because adherence to such procedures is assumed to confer 'objectivity' on their findings. Runeson (1997) equates the interpretive researcher with the perceptive researcher. We would not demur from this. Where we differ from Runeson is in our unwillingness to leave the matter of the researcher's perceptiveness to chance. On the contrary, 
such perceptiveness is the primary necessity for a management researcher and research that lacks this quality is not only bad research, it is unacceptable research. Our approach is intended to develop and exploit the researcher's perceptiveness.

What is acceptable? Though there has been much work in various social studies disciplines, to establish realistic criteria for successful research, we cannot claim to have identified a lucid model for management researchers to follow. We are still developing our approach and will continue to do so in the context of our ongoing conversation with the research community at large. We attempted to give some indication of the direction we have taken in our original paper, we will attempt to elucidate further in a future response to Runeson's (1997) staunch defence of positivism. Meanwhile, we will conclude by attempting to outline some methodological principles which we attempt to follow, in order to achieve the verstehen understanding we have called for. First, the explication of inter-subjectively established meaning is the aim of social research. Second, such explication requires the researcher to refrain from constructing theoretical explanations (including causal ones), since these impose the researcher's meanings at the expense of those of the subjects of the research. Third, therefore, the final test of the validity of an analysis is if it can be demonstrated that such an analysis is the analysis which is used by the subjects of the analysis in analysing their own situation. Fourth, there is a tension between these academic principles and the further principle that the findings of research should be useful to practitioners, in the sense that fulfilling the first cannot guarantee the second, and vice versa. Fifth, this tension can be managed on the basis that all findings are produced in specific circumstances, for specific purposes. Sixth, the research should be capable of communicating a knowledge of how others in the construction process see that process in a way that is useful to practitioners (that usefulness to be judged by the practitioners themselves). Seventh, in addition, research should enable practitioners to reflect upon their own practices in such a way as to facilitate their attempts to improve those practices.

We take it that research conducted in conformance to these principles is, if not non-existent, at least rare in construction management at the present time.

\section{References}

ANDERSON, R. J., HUGHES, J. A. \& SHARROCK, W. W. (1986) Philosophy and the human sciences, Croom Helm, London.

BLUMER, H. (1967) Sociological analysis and the variable, in BLUMER, H. Symbolic Interactionism: perspective and method, Prentice-Hall, Englewood Cliffs, 127-139. 
BUTTON, G., COULTER, J., LEE, J. R. E. \& SHARROCK, W. W. (1995) Computers, minds and conduct, Polity Press, Cambridge.

COULTER, J. (1979) The social construction of mind: studies in ethnomethodology and linguistic philosophy, Macmillan, London.

CROOK, D. J. (1997) Empirical enquiry or metaphysics? Respecifying the methodological debate, Journal of Construction Procurement, in press.

CSETE, J. M. \& ALBRECHT, R. R. (1994) The best of both worlds: synthesizing quantitative and qualitative research in the medical setting, Primary Care Research Methods and Statistics Conference, San Antonia, Texas.

EDUM-FOTWE, F., PRICE, A. D. F. \& THORPE, A. (1996) Research method versus methodology: achieving quality in scholarly research for construction management, ARCOM 96, Proceedings of the Twelfth Annual Conference of the Association of Researchers in Construction Management, Sheffield Hallam University, 10-12 September, 428-437.

HALSEY, A. H. (1996) No discouragement, Macmillan, London.

HARALAMBOS, M. \& HOLBORN, M. (1991) Sociology: themes and perspectives, Collins Educational, London.

KUHN, T. S. (1970) The Structure of Scientific Revolutions (second edition) University of Chicago Press.

RAFTERY, J., McGEORGE, D. \& WALTERS, M. (1997) Breaking up methodological monopolies: a multi paradigm approach to construction management research, Construction Management \& Economics, in press.

ROOT, D., FELLOWS, R. \& HANCOCK, M. (1997) Qualitative versus quantitative or positivism and interactionism - the superficiality of the current methodological debate, Journal of Construction Procurement, in press.

RORTY, R. (1980) Philosophy and the mirror of nature, Blackwell.

RUNESON, G. (1997) The role of theory in construction management research: comment, Construction Management \& Economics, in press.

RYLE, G. (1963) The Concept of Mind, Penguin, Harmondsworth. 
SEYMOUR, D. E., \& ROOKE, J. A. (1995) The culture of the industry and culture of research, Construction Management and Economics, 13:511-523.

SEYMOUR, D. E., SHAMMAS-TOMA, M. \& CLARK, L. A. (1997) Limitations of the use of tolerences for communicating design requirements to site, Engineering, Construction \& Architectural Management, 4:3-22

SHAMMAS-TOMA, M., SEYMOUR, D.E. \& CLARK, L., (1996) The effectiveness of formal quality management systems in achieving the required cover in reinforced concrete, Construction Management \& Economics, 14:353-364.

WAGNER, R. (1981) The Invention of Culture, University of Chicago Press, Chicago.

WINCH, P. (1990) The idea of a social science and its relation to philosophy, Second Edition, Routledge, London. 